\title{
Coronary flow reserve in adults with systemic right or single ventricles
}

\author{
Laura Olivieri ${ }^{*}$, Li-Yueh Hsu ${ }^{2}$, Anitha John', Karen Kuehl', Andrew E Arai ${ }^{2}$ \\ From 19th Annual SCMR Scientific Sessions \\ Los Angeles, CA, USA. 27-30 January 2016
}

\section{Background}

Late failure of systemic right and single ventricles is difficult to predict. Approximately $1 / 3$ of subjects with congenitally corrected transposition of the great arteries (ccTGA) have congestive heart failure by the fifth decade and $2 / 3$ of subjects with ccTGA and significant associated defects have congestive heart failure by the age of 45 years. Perfusion defects have been identified at rest in $55 \%$ of subjects with systemic right ventricles by dipyridamole sestamibi and with exercise in $45 \%$, which are not due to endovascular obstructive coronary disease. Subjects with perfusion defects typically have worse right ventricular function, but not always. It may be tied to coronary flow reserve and coronary mismatch in these hypertrophied ventricles. The objective of this study was to assess the technical feasibility of stress perfusion imaging by CMR and calculate coronary flow reserve in adults with systemic right or single ventricles.

\section{Methods}

With IRB approval and informed consent, 14 adult patients with either a systemic right ventricle or a single ventricle underwent $C M R$ with vasodilator stress perfusion imaging using adenosine $(140 \mathrm{mcg} / \mathrm{kg} / \mathrm{min})$. Data collection included stress perfusion imaging, measurement of

Table 1 Characteristics and measured myocardial blood flow and coronary flow reserve of 12 included subjects.

\begin{tabular}{|c|c|c|c|c|c|c|}
\hline Diagnosis & $\begin{array}{l}\text { Ventricular } \\
\text { morphology }\end{array}$ & $\begin{array}{l}\text { EDVi ( } \mathrm{ml} / \\
\mathrm{m} 2)\end{array}$ & $\mathrm{EF}$ & $\begin{array}{l}\text { Stress } \mathrm{MBF}(\mathrm{ml} / \mathrm{g} / \\
\min )\end{array}$ & $\begin{array}{c}\text { Rest } \mathrm{MBF}(\mathrm{ml} / \mathrm{g} / \\
\min )\end{array}$ & $\begin{array}{l}\text { Flow Reserve }(\mathrm{ml} / \mathrm{g} / \\
\text { min) }\end{array}$ \\
\hline DTGA Mustard & RV & 161.2 & $40 \%$ & 1.55 & 1.05 & 0.5 \\
\hline DTGA Mustard & RV & 107.1 & $45 \%$ & 1.11 & 0.83 & 0.28 \\
\hline $\operatorname{ccTGA}\{S, L, L\}$ & RV & 205 & $54 \%$ & 0.94 & 0.92 & 0.02 \\
\hline PA-IVS Fontan & LV & 56.4 & $58 \%$ & 0.77 & 0.73 & 0.04 \\
\hline $\operatorname{ccTGA}\{S, L, L\}$ & RV & 115.5 & $50 \%$ & 1.68 & 1.10 & 0.58 \\
\hline DTGA Mustard & RV & 111.7 & $53 \%$ & 2.07 & 1.14 & 0.93 \\
\hline DILV, $\{S, L, L\}$ Fontan & LV & 104.1 & $63 \%$ & 1.07 & 0.83 & 0.24 \\
\hline DTGA Senning & RV & 124.7 & $45 \%$ & 2.05 & 1.28 & 0.77 \\
\hline HLHS Fontan & RV & 95.5 & $65 \%$ & 1.7 & 1.23 & 0.47 \\
\hline $\operatorname{ccTGA}\{S, L, L\}$ & RV & 90.6 & $50 \%$ & 2.13 & 0.9 & 1.23 \\
\hline $\begin{array}{l}\text { ccTGA, VSD s/p } \\
\text { closure }\end{array}$ & RV & 153.9 & $50 \%$ & 2.99 & 1.26 & 1.73 \\
\hline DILV, Fontan & LV & 57 & $68 \%$ & 1.64 & 0.76 & 0.88 \\
\hline
\end{tabular}

(ccTGA congenitally corrected Transposition of the great arteries, DTGA D-transposition of the great arteries, PA-IVS pulmonary atresia with intact ventricular septum, DILV double inlet left ventricle, HLHS hypoplastic left heart syndrome, VSD ventricular septal defect, EDVi end-diastolic volume indexed to body surface area, EF ejection fraction, MBF myocardial blood flow).

${ }^{1}$ Children's National Medical Center, Washington, DC, USA

Full list of author information is available at the end of the article

(c) 2016 Olivieri et al. This is an Open Access article distributed under the terms of the Creative Commons Attribution License (http:// creativecommons.org/licenses/by/4.0), which permits unrestricted use, distribution, and reproduction in any medium, provided the original work is properly cited. The Creative Commons Public Domain Dedication waiver (http://creativecommons.org/publicdomain/ zero/1.0/) applies to the data made available in this article, unless otherwise stated. 


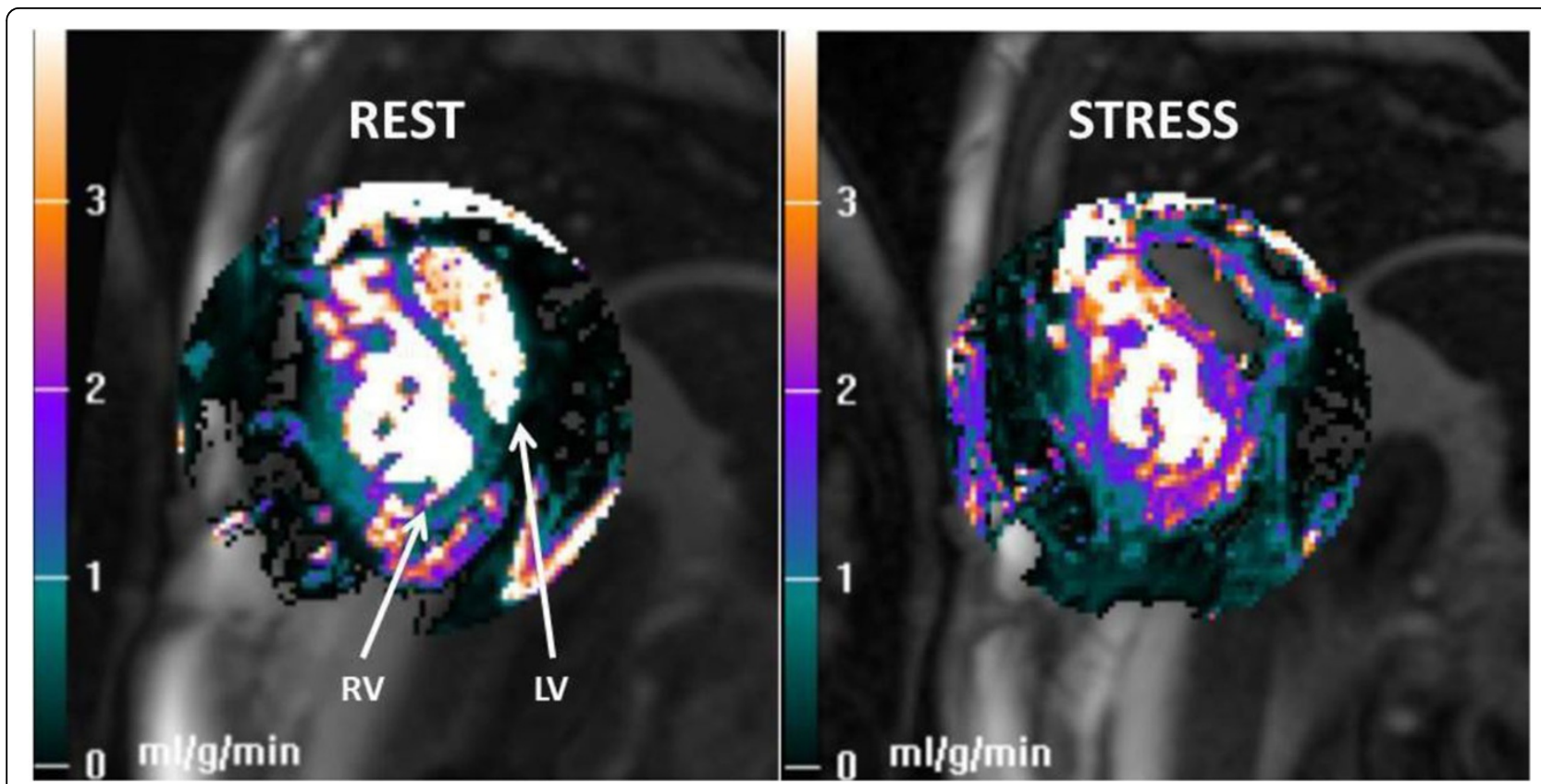

Figure 1 Quantitative pixel maps showing myocardial blood flow values for a patient with D-TGA s/p Mustard at rest (left) and during adenosine stress (right).

cardiac volume metrics and rest perfusion imaging at least 20 minutes after adenosine. Global myocardial blood flow $(\mathrm{MBF})$ in $\mathrm{ml} / \mathrm{min} / \mathrm{g}$ and coronary flow reserve (CFR) were quantified using a fully quantitative model constrained deconvolution. Subjects underwent additional data collection, including lab work, 6-minute walk test and ECG.

\section{Results}

Table 1 summarizes patient characteristics and salient testing results. Two of 14 perfusion studies were not quanitifiable; one due to an incomplete first pass of contrast likely related to low EF, one had technical issues during imaging. Of the remaining 12 subjects, 10 had a measureable change in myocardial blood flow, and 2 did not. Stress measurements of myocardial blood flow were lower in most patients than established MBF values in normal ventricles. Figure 1 demonstrates the global myocardial blood flow at rest and during stress of a patient with high CFR.

\section{Conclusions}

Myocardial blood flow and coronary flow reserve are quantifiable with current techniques regardless of ventricular morphology. This technique shows promise as a potential method of risk stratification of this population.

\section{Authors' details}

${ }^{1}$ Children's National Medical Center, Washington, DC, USA. ${ }^{2}$ National Heart, Lung and Blood Institute, Bethesda, MD, USA.
Published: 27 January 2016

doi:10.1186/1532-429X-18-S1-P173

Cite this article as: Olivieri et al:: Coronary flow reserve in adults with systemic right or single ventricles. Journal of Cardiovascular Magnetic Resonance 2016 18(Suppl 1):P173.

\section{Submit your next manuscript to BioMed Central} and take full advantage of:

- Convenient online submission

- Thorough peer review

- No space constraints or color figure charges

- Immediate publication on acceptance

- Inclusion in PubMed, CAS, Scopus and Google Scholar

- Research which is freely available for redistribution
Bïmed Central 